\title{
Crença e conhecimento em Nietzsche
}

\author{
André Luís Mota Itaparica*
}

\begin{abstract}
Resumo: Segundo uma tradicional concepção epistemológica, conhecimento é crença verdadeira justificada. Essa concepção pressupõe que três condições devam ser satisfeitas para que tenhamos conhecimento. Podemos dizer que $\mathrm{S}$ conhece que $p$ se e somente se: (1) $p$ é verdadeira, (2) $\mathrm{S}$ crê que $p$ e (3) S está justificado em acreditar que $p$. Podemos extrair das reflexões epistemológicas de Nietzsche três perguntas endereçadas a essa concepção de conhecimento: (1) O que significa possuir uma crença? (2) O que torna uma crença verdadeira? (3) É possível uma justificativa racional para nossas crenças?
\end{abstract}

Palavras-chave: crença - conhecimento - verdade

\section{Introdução}

Uma resposta para a questão de como uma crença alcança o estatuto de conhecimento foi apresentada no Teeteto (201c-d), de Platão, tornando-se uma concepção de conhecimento clássica: conhecimento é crença verdadeira justificada. Como se sabe, essa concepção pressupõe que três condições devam ser satisfeitas para que tenhamos conhecimento. Podemos dizer que $\mathrm{S}$ conhece que $p$ se e somente se: (1) $p$ é verdadeira, (2) S crê que $p$ e (3) S está justificado em acreditar que $p$. As condições (1), (2) e (3) seriam assim necessárias e suficientes para alguém conhecer a proposição $p^{1}$.

\footnotetext{
* Professor da Universidade Federal do Recôncavo da Bahia (UFRB). Endereço eletrônico: itapa71@gmail.com.

1 GETTIER, Edmund. “Is true belief knowledge?” In: Analysis (v. 23, n. 6), 1963, pp. 121-123.
} 
Itaparica, M. L. A.

Embora Nietzsche, pelo menos até onde sabemos, nunca tenha explicitamente se pronunciado a respeito dessa formulação, podemos extrair de suas reflexões epistemológicas três perguntas endereçadas a essa concepção de conhecimento: (1) O que significa possuir uma crença? (2) O que torna uma crença verdadeira? (3) É possível uma justificativa racional para nossas crenças? Para respondê-las, Nietzsche recorre a uma abordagem de caráter genético-naturalista, que mostrará a implicação de toda crença com uma noção de verdade, concluindo enfim pela impossibilidade de uma justificativa racional última para a admissão de nossas crenças. Com isso, Nietzsche defenderá uma concepção de conhecimento de caráter pragmatista e falibilista.

\section{O que significa possuir uma crença?}

A questão do conhecimento resume-se em Nietzsche a uma questão bastante precisa: como sabemos que possuímos conhecimento? Para ele, uma teoria do conhecimento não pode deixar de fazer essa pergunta fundamental, que afinal era a mesma pergunta de Platão no Teeteto: o que é conhecimento? Uma teoria do conhecimento que apenas procura as fontes e os fundamentos de um conhecimento toma esse conhecimento como um fato, sem se interrogar sobre o que nos faz considerar determinadas crenças conhecimento, ignorando assim a própria questão do conhecimento:

"É o conhecimento afinal um fato? O que é o conhecimento? Se não soubéssemos o que é o conhecimento, seria impossível responder à questão se há conhecimento. Muito bem! Mas se eu sequer 'sei' se há conhecimento, se pode haver conhecimento, não posso formular a questão 'o que é conhecimento' de maneira alguma. (...)" (NACHLASS/FP 7 [4], KSA 12.264).

202 | Cad. Nietzsche, Guarulhos/Porto Seguro, v.36 n.2, p. 201-218, 2015. 
Nietzsche parece apontar, então, para um paradoxo na pretensão de constituição de uma teoria do conhecimento: de um lado, se não soubermos o que é conhecimento, a pergunta sobre o que é conhecimento permanecerá sem resposta, pois não saberemos que condições devem ser satisfeitas para que possamos atribuir a determinadas crenças o estatuto de conhecimento; de outro lado, se soubermos o que é conhecimento, a pergunta pelo que é conhecimento não será uma questão legítima, já que ela é entendida não como uma pergunta sobre a natureza do conhecimento, mas como a busca de uma justificativa filosófica sobre um conhecimento que já tomamos como dado. Esse parece ser o caso da concepção segundo a qual o conhecimento é crença verdadeira justificada. A primeira questão a ser respondida, então, é entender o que significa possuir uma crença, que é o conceito nuclear dessa concepção de conhecimento.

Nietzsche afirma, na mesma anotação do espólio acima citada: “CConhecer é julgar”. Mas o juízo é uma crença de que algo é tal e qual! E não conhecimento!” (NACHLASS/FP 7 [4], KSA 12.264). O que Nietzsche indica nessa passagem é que na formulação de um juízo já se encontram presentes crenças prévias sobre a natureza da linguagem e da realidade, e por isso a questão para ele se reformula na pergunta do que significa possuir uma crença que se expressa num juízo: "No juízo se esconde uma crença de que 'isto é de tal e tal modo', como se justamente a própria crença fosse o fato mais próximo que podemos afirmar! Como é possível crer?" (NACHLASS/ FP 26 [65], KSA 11.166). A pergunta sobre a natureza da crença, assim, se torna um problema central para o que consideramos conhecimento. Antes de discutir a veracidade de nossas crenças e procurar justificá-las é necessário, para Nietzsche, incialmente entender o que significa possuir uma crença, no sentido de entender como nossas crenças são formadas e fixadas. 
Itaparica, M. L. A.

A questão que se coloca, então, passa a ser o que é possuir uma crença. Nietzsche considera que uma crença significa tomar algo por verdadeiro [für wahr halten]. Quem emite um juízo possui a crença de que afirma algo verdadeiro, ou seja, de que no plano da realidade algo é de tal ou tal modo. O juízo é, então, antes de tudo, a expressão de uma crença de que entre o próprio juízo e os fatos existe uma correspondência que o torna verdadeiro. A teoria da verdade como correspondência se revela, assim, como uma crença pré-teórica, prévia e espontânea, que se apresenta como pano de fundo na formação de qualquer juízo.

A esse respeito, devemos observar que Nietzsche faz um uso ambivalente do termo "juízo". Juízo significa tanto o ato mental de unir representações quanto a proposição contida no produto desse ato mental e expressa em um enunciado. Essa imbricação não será sem consequências. Além do ato psicológico de unir representações e formulá-las em um enunciado que pretende descrever, de maneira verdadeira, os fatos, o estudo de Nietzsche do juízo como um processo psicológico também levará em conta as crenças prévias que sustentam um juízo. Em Nietzsche, o lógico e o psicológico serão dois níveis de um mesmo processo, no qual o psicológico desempenha um papel fundante em relação ao lógico. As categorias lógicas, desse modo, serão sempre remetidas aos seus correlatos psicológicos, que se constituem como gênese das primeiras: "Todas as nossas categorias da razão possuem origem nos sentidos: [são] derivadas do mundo empírico" (NACHLASS/FP 9 [98], KSA 12.391).

Por isso poderíamos dizer que toda crença já traz consigo uma outra crença: a pretensão de que a proposição que exprime o conteúdo do juízo corresponde verdadeiramente a fatos. Nietzsche considera que há aí crenças metafísicas prévias, embutidas na teoria da predicação, cujas origens psicológicas ele se incube de traçar. Se

204 Cad. Nietzsche, Guarulhos/Porto Seguro, v.36 n.2, p. 201-218, 2015. 
as categorias lógicas possuem origem psicológica, essa psicologia, por sua vez, é compreendida em termos naturalistas, cujo resultado podemos adiantar aqui: a enunciação de um juízo já pressupõe uma teoria da predicação que está enraizada em experiências psicológicas, que provêm, por sua vez, de uma origem biológica, e é neste estrato que nossas crenças são formadas e fixadas.

Em suas hipóteses genéticas sobre a origem da lógica, Nietzsche considera que os princípios mais básicos da lógica, como o de identidade, por exemplo, poderiam ser explicados a partir de uma análise de sua origem empírica: "Para a compreensão da lógica: - a crença de algo seja tal e tal (a essência do juízo) é consequência de uma vontade de que, tanto quanto possível, deva haver coisas iguais" (NACHLASS/FP 2 [90], KSA 12.106). Esse princípio pode ser filogeneticamente remetido a uma necessidade biológica de simplificar e estabilizar as informações do meio ambiente para fins de sobrevivência, tendo como objetivo proporcionar uma vantagem evolutiva, já que um mundo percebido em constante transformação ofereceria maiores dificuldades para a conservação da vida. O juízo é assim entendido como a formulação já linguisticamente articulada de uma forma de percepção do meio ambiente que se tornou necessária e útil para que os indivíduos da espécie humana possam agir de tal modo que consigam assegurar sua sobrevivência. A linguagem, nesse contexto, seria também produto da necessidade de comunicação com os semelhantes, em uma rede auxílio de animais sociais diante dos desafios impostos pela natureza. Dessa necessidade de comunicação surge uma linguagem predicativa, que acabará por interpretar e dispor a realidade a partir de sua estrutura gramatical. É que Nietzsche chama de "filosofia comum da gramática".

Para Nietzsche, assim, a estrutura gramatical das diversas línguas reflete condições biológicas determinantes, que 
Itaparica, M. L. A.

produzem esquemas a partir dos quais organizamos a realidade, a fim de orientar nosso comportamento. Por esse motivo, segundo Nietzsche, há espantosas semelhanças de família [FamilienAhnlichkeiten] entre filosofias de um mesmo ramo linguístico: "o encanto [Bann] exercido por determinadas funções gramaticais é, em última instância, o encanto de condições raciais e juízos de valor fisiológicos" (JGB/BM 20, KSA 5.34). Em nosso caso, a forma sujeito-predicado é tomada como uma estrutura lógica que corresponde à forma substância-acidente na realidade, que é considerada, por sua vez, como independente em termos metafísicos. Com essas considerações, Nietzsche está afirmando que na teoria da predicação há uma imbricação inevitável entre lógica e ontologia. Como resultado, transpomos uma estrutura gramatical à realidade, acreditando que haja uma isomorfia entre linguagem e mundo. E, coerente com sua remissão de categorias lógicas a suas origens psicológicas, Nietzsche apontará na raiz das categorias lógicas a ilusão psicológica de um sujeito dotado de uma vontade eficiente: “Os postulados lógico-metafísicos, a crença em substância, acidente, atributo, etc. derivam sua força persuasiva do hábito de ver todas nossas ações como efeito [Folge] de nossa vontade" (NACHLASS/FP 9 [98], KSA 12.391)2.

Ao emitir um juízo, portanto, já estamos admitindo que a própria forma do juízo é capaz de expressar uma isomorfia entre proposição e fato. Isso quer dizer que na própria expressão de uma crença já estamos assumindo crenças prévias a respeito da estrutura da linguagem e da estrutura do mundo. Se para o lógico é irrelevante uma explicação genético-psicológica da forma do juízo, para Nietzsche essa explicação é importante para termos ideia do

2 Desenvolvemos essa argumentação em: ITAPARICA, A. L. M. "Nietzsche: crítica à metafísica como crítica à linguagem”. In: LIMA, M. J. S.; ITAPARICA, A. L. M. (Org.). Verdade e linguagem em Nietzsche. 1ed. Salvador: Edufba, 2014, v. 1, p. 105-119.

206 Cad. Nietzsche, Guarulhos/Porto Seguro, v.36 n.2, p. 201-218, 2015. 
que está envolvido em nossas crenças e para nos perguntar até que ponto podemos justificar nossa pretensão de encontrar um critério racional último de validação de nossas crenças.

O que é então para Nietzsche possuir uma crença? Para ele possuir uma crença significa formar um juízo a partir de um pano de fundo de crenças prévias que são adquiridas e fixadas para orientar o comportamento de uma espécie na luta pela sobrevivência. É esse contexto naturalista que nos fornecerá, também, os critérios para estabelecer a verdade ou falsidade de uma crença.

\section{Que critério de verdade temos à disposição para afirmar ou negar uma crença?}

Quando tomamos uma crença por verdadeira já pressupomos de antemão que a verdade de uma crença é a correspondência do juízo que a exprime com a realidade. Isso pressupõe, por sua vez, a crença metafísica de que o mundo tenha uma estrutura fixa que a linguagem reflete. Em sua gênese naturalista de nossas crenças, Nietzsche considerará que a linguagem é uma habilidade que garante uma vantagem evolutiva para a espécie humana; do mesmo modo, a crença de que o mundo possua uma estrutura estável se deve também a vantagens evolutivas. Para sobreviver, o homem possui faculdades que estabilizam o fluxo de sensações que experimenta, organizando esse fluxo por meio de uma mente já estruturada linguisticamente. A convicção de que a verdade seja correspondência nada mais é que um expediente útil para a sobrevivência. A verdade, assim, significa utilidade e não uma relação metafísica entre linguagem e mundo: "A avaliação 'eu creio que isso é tal e tal' como a essência da 'verdade'. Em avaliações se expressam condições de preservação e crescimento. A confiança 
Itaparica, M. L. A.

na razão e em suas categorias, na dialética, portanto a avaliação da lógica, prova apenas sua utilidade, demonstrada pela experiência, para a vida: não sua "verdade" (NACHLASS/FP 9 [38], KSA 12.352).

Quando julgamos estamos portanto expressando nossa crença de que há uma correlação entre juízo e mundo, que quando são correspondentes tornam o juízo verdadeiro. A verdade, assim, é correspondência. Essa ideia de verdade já está pressuposta na própria teoria da predicação. Para Nietzsche, a verdade como correspondência, embora seja a mais natural e espontânea, tanto que é nela que se baseia a metafísica que sustenta nossas crenças, encontra sérios problemas quando interrogada de forma mais acurada. Ela é inconsistente, pois não há como ultrapassarmos nossas faculdades cognitivas para saber se nossas representações correspondem ou não ao mundo, como se houvesse um ponto de vista exterior a todos os pontos de vista, um ponto de vista do olhar divino. Nietzsche chama de perspectivismo essa dependência de nossas descrições do nosso ponto de vista. Não podemos assim atingir um ponto de vista exterior e imparcial. Nietzsche aponta aqui para a incoerência da pretensão de ter conhecimento de uma realidade metafísica, independente de nossas faculdades cognitivas, de nossa linguagem e de nossos interesses práticos.

Para Nietzsche, a ideia de correspondência só se sustentaria pela admissão de uma realidade metafísica sobre a qual não podemos nos certificar. O alvo da crítica da verdade como correspondência em Nietzsche, no entanto, não reside tanto na admissão desses pressupostos, mas na pretensão que temos de justificá-los, o que está além de nossas capacidades. Por isso, a verdade de uma crença, tomando "verdade" na acepção adotada pela teoria da correspondência, não será indispensável para a adoção dessa crença:

A falsidade de um juízo não chega a constituir, para nós, uma

208 Cad. Nietzsche, Guarulhos/Porto Seguro, v.36 n.2, p. 201-218, 2015. 
objeção contra ele; é talvez neste ponto que a nossa nova linguagem soa mais estranha. A questão é em que medida ele promove ou conserva a vida, conserva ou até mesmo cultiva a espécie; e somos fundamentalmente tentados a afirmar que os juízos mais falsos (...) nos são os mais indispensáveis (JGB/BM 4, KSA 5.18) ${ }^{3}$.

Passagens de Nietzsche como esta agora citada possuem uma ambiguidade incontestável, que se não for esclarecida pode ser entendida como uma contradição. Ao falar da falsidade de um juízo, Nietzsche certamente está adotando o ponto de vista da verdade como correspondência, que é, no entanto, o próprio objeto de sua crítica. Atento a essa ambiguidade, o próprio Nietzsche refere-se à estranheza de sua linguagem. Mas essa aparente contradição é resolvida se notarmos que Nietzsche propositadamente, e com finalidade polêmica, tem em mente nessa e outras passagens dois sentidos de verdade. De um lado, a verdade pode ser entendida como correspondência, e é nesse sentido que Nietzsche diz que nossos juízos são falsos, ou seja, se adotarmos a verdade como correspondência como critério, não temos como garantir que nossos juízos reflitam uma alegada realidade metafísica. De outro lado, Nietzsche adota no mesmo contexto um conceito mais amplo de verdade: ele envolve não a correspondência, mas a utilidade em termos biológicos que uma determina crença propicia. Verdade, assim, será uma espécie de erro (erro entendido em termos correspondentistas) que se mostrou mais útil: "A verdade é uma espécie de erro sem o qual certas espécies de vida não poderiam viver. O valor para vida é definitivamente decisivo" (NACHLASS/FP 34 [253], KSA 11.506). Quando falamos de uma crença verdadeira, desse modo, estamos falando de um juízo que é, em termos

3 Tradução de Paulo César de Souza.

Cad. Nietzsche, Guarulhos/Porto Seguro, v.36 n.2, p. 201-218, 2015. 
Itaparica, M. L. A.

biológicos, uma avaliação sobre a realidade (como uma disposição para um comportamento), que consideramos, por motivos utilitários, corresponder a ela: “Qual é a crença mais desejável e útil? (quando não se chega à verdade), pode-se perguntar. Mas para isso se tem de perguntar ainda: útil para quê?" (NACHLASS/FP KSA 26 [83], 11.170). Útil para a vida é um critério geral, ao qual as crenças singulares estão submetidas em situações específicas. Com isso, a noção de verdade de Nietzsche ganha uma grande maleabilidade, pois são em contextos pragmáticos que podemos aferir a verdade ou falsidade de uma crença.

Mas a pergunta sobre qual é a crença mais útil parece nos reservar uma resposta surpreendente: a ideia da verdade como correspondência talvez seja uma das nossas crenças mais úteis, pois, motivada por uma necessidade biológica de dominar a realidade, nos fornece um critério eficaz, em termos práticos, para aferir nossas crenças, no contexto da preservação da vida, embora em termos estritamente teóricos e metafísicos não seja capaz de satisfazer seus próprios pressupostos.

A verdade como correspondência é por isso a forma mais natural de nos certificarmos da verdade de nossos juízos: ela toma por dada uma realidade organizada em grande medida por nossas faculdades e procura ver se há uma adequação entre nossos juízos e essa realidade. Nietzsche parece querer dizer, portanto, que sua crítica à verdade como correspondência visa a atingir mais sua pretensão de justificação do que negar sua utilidade em grande número de contextos. Por isso ela pode ser substituída por um critério mais amplo, que inclusive englobe a própria noção de correspondência. A verdade como correspondência, assim, aparece como uma espécie pertencente ao gênero de verdade pragmatista que Nietzsche defende. A ênfase não está na própria ideia de correspondência, mas em sua impossibilidade, quando observada a metafísica realista que a sustenta: a suposição de que haja um objeto descrito que já não

210 Cad. Nietzsche, Guarulhos/Porto Seguro, v.36 n.2, p. 201-218, 2015. 
seja em alguma medida dependente da descrição ${ }^{4}$.

Ou seja, mesmo que um juízo seja falso nos critérios de correspondência - e, para Nietzsche, se se assumirem as exigências rígidas de um realismo metafísico, assim sempre o será - isso não é motivo para descartá-lo, pois verdade e falsidade, no fim, nada mais são que funções da utilidade das nossas crenças: "Podese acreditar, com força, numa coisa: nisto repousa o critério de verdade'. Mas o que é a verdade? Talvez uma forma de crença que se tornou condição de vida? Pois a força seria um critério" (Nachlass/FP 40 [15], KSA 11.635). Uma crença verdadeira, enfim, é uma crença que, sob determinados aspectos, se mostrar mais útil: “'A verdade': isso, de acordo com minha forma de pensar, não denota necessariamente a antítese do erro, mas nos casos mais fundamentais somente a postulação de vários erros em relação uns com os outros" (NACHLASS/FP 38 [4], KSA 11.598). Esses "erros", entendidos em termos correspondentistas, são justamente as nossas crenças prévias sobre o mundo que são o pano de fundo para a formulação de nossos juízos. Não se pode falar em verdade de um juízo singular sem a pressuposição de uma rede de juízos implícitos que constituem uma teia de crenças prévias que garantem a inteligibilidade de nossos enunciados: "Não há nenhum juízo singular! Um juízo singular nunca é 'verdadeiro', nunca é conhecimento, somente em conexão, em relação como outros juízos, ele tem direito de cidadania" (NACHLASS/FP 7 [4], KSA 12.265). E para mostrar que não podemos ir além disso em nossas pretensões a respeito da posse da verdade, Nietzsche enfim desvelará a inviabilidade das tentativas de justificar nossas crenças que consideramos verdadeiras em bases puramente racionais.

4. Sobre a compatibilidade entre uma concepção pragmatista de verdade e a teoria da verdade como correspondência, em William James, por exemplo, ver: PUTNAM, H. Corda tripla. Mente corpo e mundo. Aparecida: Ideia \& Letras, 2008, 17-19. 
Itaparica, M. L. A.

\section{Como posso justificar as crenças que tomo por verdadeiras?}

Como vimos, o juízo já pressupõe uma crença de que o conteúdo da proposição corresponde de alguma maneira à realidade, o que garante a verdade da crença expressa nesse juízo. Em todo juízo, assim, já está pressuposta uma teoria da verdade como correspondência. Em sua análise genética, Nietzsche remeterá essa concepção a uma necessidade biológica, submetendo esse critério ao critério mais amplo de utilidade para a vida. Por isso nossas crenças verdadeiras (em sentido correspondentista) não são racionalmente justificáveis. Mas como se pensou que se poderia passar da crença subjetiva na verdade de um juízo - fruto de necessidades biológicas - para a sua validade objetiva, quando justifico racionalmente minha crença? Em outras palavras, como se procurou a certificação de minhas crenças? Para Nietzsche, isso se deu por meio ao recurso a critérios subjetivos de evidência e de certeza imediata, aos quais ele então reserva um longo debate.

Nessa questão, Nietzsche mira a concepção cartesiana segundo a qual a forma evidente pela qual algumas representações mentais se apresentam à consciência garante a certeza das crenças que elas expressam, e com isso sua verdade ${ }^{5}$. Nietzsche se concentra sobretudo na ideia de que o cogito seja o resultado de uma certeza imediata, independente de qualquer crença prévia: "se eu decomponho o processo que está expresso na proposição 'eu penso', obtenho uma série de afirmações temerárias, cuja fundamentação é difícil, talvez impossível (JGB/BM 16, KSA 5.29). Para Nietzsche, o

5 Desenvolvi essa questão em: ITAPARICA, A. L. M. "Crítica da modernidade e conceito de subjetividade em Nietzsche". Branco, Maria João Mayer; Constâncio, João. (Org.). Sujeito, decadência e arte: Nietzsche e a modernidade. led.Lisboa: Tinta da China, 2014, v. 1, p. 39-60.

212 | Cad. Nietzsche, Guarulhos/Porto Seguro, v.36 n.2, p. 201-218, 2015. 
cogito pressupõe a crença no sujeito, no pensamento como atividade, e uma concepção do que significa existir. A suposta evidência do cogito, portanto, já está enredada em uma série de crenças prévias. Há um elemento categorial prévio, quando Descartes considera indissociáveis pensamento e existência, ou seja, há crenças tácitas sobre a natureza do existência e do pensamento. $\mathrm{O}$ mais importante aqui não é a fidelidade da análise pontual que Nietzsche faz do cogito cartesiano, mas sua conclusão: não há nenhuma certeza que já não esteja baseada em crenças anteriores, que servem de pano de fundo para a própria inteligibilidade de nossa reflexão. Para Nietzsche, a mera consciência de estados mentais como os de certeza imediata ou evidência não é, por si só, uma justificativa sustentável, pois os efeitos que uma crença provoca em mim não é garantia de sua verdade. Uma crença pode ser agradável, edificante ou até mesmo irrefutável por critérios lógicos e nem por isso ter qualquer referência ao real, pois a força de uma crença confirma apenas a sua própria força, e não sua verdade: “Uma hipótese [Annahme] que é irrefutável - por que ela deveria por isso ser verdadeira? Essa proposição talvez irrite os lógicos, que avaliam [ansetzen] seus limites como limites das coisas" (NACHLASS/FP 38 [4], KSA 11.598). Foi assim que Descartes, de um critério interno de verdade - clareza e distinção de ideias - considerou poder extrair um conhecimento:

A certeza [Bestimmtheit] lógica, a transparência como critério da verdade ["omne illud verum est, quod clare et distincte percepitur"] (Descartes) (...). Mas isso é uma confusão grosseira: assim como simplex sigillum veri. De onde se sabe que que a verdadeira natureza [Geschaffenheit] das coisas está nesse relação com nosso intelecto? (NACHLASS/FP 9 [91], KSA 12.386).

Nenhum critério interno é capaz de nos assegurar uma certeza sobre algo que transcende o âmbito subjetivo, pois essa certeza é resultado de impressões que certos conteúdos produzem na própria 
Itaparica, M. L. A.

mente, e já pressupõe um pano de fundo de crenças. Em suma, para Nietzsche todas nossas crenças estão tão envolvidas e sustentadas por outras crenças que não temos um ponto arquimediano sobre o qual possamos justificá-las.

\section{O que é conhecimento para Nietzsche?}

Nietzsche, como vimos, apresentou uma série de questões à tradicional formulação de que conhecimento é crença verdadeira justificada. Seu propósito era mostrar que: (1) Uma crença é a base de um juízo que expressa uma avaliação a partir de determinadas condições de existência; (2) Essas condições de existência determinam o que consideramos verdadeiro; (3) Não há nenhum critério interno capaz de justificar a certeza de nossas crenças.

Desse modo, o que determinará para Nietzsche a passagem de uma crença ao estatuto de conhecimento será sua utilidade biológica. Em um movimento similar ao que ele realizou em relação à noção de verdade, Nietzsche também diferenciará conhecimento enquanto crença verdadeira justificada (com todos os pressupostos metafísicos presentes nessa concepção) e conhecimento enquanto função de uma adaptação para fins de sobrevivência: “É improvável que nosso 'conhecimento' devesse se estender além do que é estritamente necessário para a preservação da vida" (NACHLASS /FP 36 [19], KSA 11.559). Nesse sentido, o conhecimento em Nietzsche assume conotações que podemos considerar pragmatistas, já que ele também abdica de compromissos ontológicos fortes, quando defende uma imbricação entre descrição e objeto descrito e afirmando a utilidade biológica como critério de conhecimento: “O significado de 'conhecimento': (...) o conceito deve ser visto em sentido estritamente antropocêntrico e biológico.

214 Cad. Nietzsche, Guarulhos/Porto Seguro, v.36 n.2, p. 201-218, 2015. 
A fim de uma espécie particular se manter e incrementar seu poder, sua concepção de realidade deve compreender muito de calculável e constante para basear um esquema de comportamento nele" (NACHLASS /FP 14 [122], KSA 13.302) ${ }^{6}$.

Não temos para Nietzsche, assim, uma justificativa racional última para o conhecimento, e nem precisamos de tal justificativa. A ausência de um fundamento último para nossas crenças epistemológicas não significa a bancarrota da ciência. Ao contrário, a ampliação pragmatista da noção de conhecimento nos fornece um critério para a escolha de teorias científicas, sem ter de recorrer a um realismo metafísico. Não termos essa âncora metafísica não significa para Nietzsche abdicar a uma noção de objetividade, só que não mais entendida como resultado um ponto de vista neutro e desinteressado, mas como a adoção de pontos de vista mais abrangentes: "Existe apenas uma visão perspectiva, apenas um 'conhecer' perspectivo, e quanto mais afetos permitirmos falar sobre uma coisa, quanto mais olhos, diferentes olhos, soubermos utilizar para essa coisa, tanto mais completo será o 'conceito' dela, nossa 'objetividade"” (GM/GM, III, 12, KSA 5.313). Assim como para Nietzsche a sua própria posição epistemológica é mais satisfatória por abarcar um maior número de teorias, é a abrangência de uma teoria científica que serve como critério para sua adoção em detrimento de outras teorias concorrentes. Nietzsche, por exemplo, defende uma teoria dinâmica da realidade em oposição a uma estritamente mecânico-materialista, mas não porque aquela

6 A ideia de uma teoria pragmatista da verdade e do conhecimento pode parecer um anacronismo. Contudo, além de ser defendida por leituras como a de Arthur Danto (DANTO, A. Nietzsche as Philosopher. New. York: Macmillan, 1965) e a neopragmatista de Richard Rorty, encontramos também elementos históricos pertinentes para sua justificação: Stack aponta para Nietzsche como fonte da versão europeia do pragmatismo (o humanismo pragmatista de F. C. S. Schiller). Cf. STACK, G. "Nietzsche's Influence on Pragmatic Humanism". In: Journal of the History of Philosophy, Volume 20, Number 4, October 1982, pp. 369-406. 
Itaparica, M. L. A.

se aproximaria mais de uma realidade metafísica do que esta, mas porque a teoria dinâmica descreveria um número maior de fenômenos físicos. Essa posição, por sua vez, confere à concepção nietzschiana de conhecimento um inegável tom falibilista, já que a produção da verdade é vista como um processo infinito: "Verdade" portanto ação é algo que deva ser encontrado ou descoberto mas algo que deve ser criado e que dá nome a um processo (...) verdade como um processus in infinitum, um determinar ativo - $\mathrm{e}$ não um tornar-se consciente de algo que fosse em si mesmo fixo e determinado" (NACHLASS /FP 9 [91], KSA 12.385).

\footnotetext{
Abstract: According to a traditional epistemological conception, knowledge is justified true belief. This conception presupposes that three conditions must be satisfied in order to someone to be in possession of knowledge. $\mathrm{S}$ knows $p$ if and only if: $p$ is true, $\mathrm{S}$ believes that $p$ and (3) $\mathrm{S}$ is justified in believing that $p$. From Nietzsche's point of view, it is possible to ask three questions to that conception of knowledge: (1) What does it mean to have a belief? (2) What makes a belief true? (3) Is it possible a rational justification for our beliefs?

Keywords: belief - knowledge - true
}

\section{referências bibliográficas}

DANTO, A. Nietzsche as Philosopher. New. York: Macmillan, 1965.

GETTIER, Edmund. "Is true belief knowledge?” In: Analysis (v. 23, n. 6), 1963, pp. 121-123.

ITAPARICA, A. L. M. “Nietzsche: crítica à metafísica como crítica à linguagem”. In:

LIMA, M. J. S. ; ITAPARICA, A. L. M. (Org.). Verdade e linguagem em Nietzsche. 1ed.

Salvador: Edufba, 2014.

216 Cad. Nietzsche, Guarulhos/Porto Seguro, v.36 n.2, p. 201-218, 2015. 


\section{Crença e conhecimento em Nietzsche}

- "Crítica da modernidade e conceito de subjetividade em Nietzsche". In:

MARTON, Scarlett; Branco, Maria João Mayer; Constâncio, João. (Org.). Sujeito, decadência e arte: Nietzsche e a modernidade. led.Lisboa: Tinta da China, 2014.

NIETZSCHE, F. Além do bem e do mal. Trad. Paulo César de Souza. São Paulo, Companhia das Letras, 1992.

- Genealogia da moral. Trad. Paulo César de Souza. São Paulo, Companhia das Letras, 2009.

. Sämtliche Werke: Kritische Studienausgabe (KSA). Berlin/München: Walter de Gruyter/ dtv, 1988.

PLATÃO. Teeteto. Trad. C. A. Nunes. Belém: Editora da UFPA, 1988.

PUTNAM, H. Corda tripla. Mente corpo e mundo. Aparecida: Ideia \& Letras, 2008.

STACK, G. "Nietzsche's Influence on Pragmatic Humanism". In: Journal of the History of Philosophy, Volume 20, Number 4, October 1982, pp. 369-406.

Artigo recebido para publicação em 15 de junho de 2015.

Artigo aceito para publicação em 28 de setembro de 2015.

Cad. Nietzsche, Guarulhos/Porto Seguro, v.36 n.2, p. 201-218, 2015. | 
